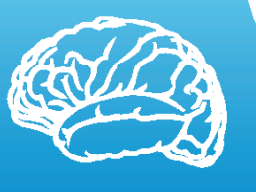

NEUROLOGY
1) Morphological Sciences Department, Iuliu Hatieganu University of Medicine and Pharmacy Cluj-Napoca, Romania

2) Radiotherapy Department, Iuliu Hatieganu University of Medicine and Pharmacy Cluj-Napoca, Romania

3) Histology and Dermatology Department, Iuliu Hatieganu University of Medicine and Pharmacy Cluj-Napoca, Romania
DOI: $10.15386 / \mathrm{mpr}-1235$

Manuscript received: 14.11 .2018

Received in revised form: 20.01.2019

Accepted: 03.02.2019

Address for correspondence:

ghebanbogdan@yahoo.com

\section{The morphological and functional characteristics of the pineal gland}

Bogdan Alexandru Gheban ${ }^{1}$, Ioana Andreea Rosca², Maria Crisan ${ }^{3}$

\begin{abstract}
Introduction. The pineal gland is a photo-neuro-endocrine organ situated inside the brain, that secretes serotonin, melatonin and N,N-dymethyltriptamine. This narrative review will address the latest information gathered on this function of the gland as well as the unknown roles it may have. The different histological and pathological findings of the pineal gland have demonstrated a role in clinical manifestations of numerous endocrine, neurological and psychiatric pathologies.
\end{abstract}

Materials. For this narrative review we used the NCBI website database PubMed. The search terms were "Pineal Gland" AND/OR "histology, melatonin, DMT, pathology". Total number of articles included were 86 .

Results. We have reviewed physiological information of melatonin and DMT, anatomical, histological and histopathological information on the pineal gland and its role in endocrine, neurological and psychiatric pathology.

Conclusion. The role of melatonin in immunity and its potential therapeutic effects show promising potential for further research. DMT seems to have a role in psychiatric pathology and potential therapeutic effects. Proper tumoral screening and diagnostic protocol are required.

Keywords: pineal gland, melatonin, calcifications, histology, pathology

\section{Background}

This narrative review will integrate both old and recent information regarding the history, anatomy, histology, physiology, pathology and clinical implications of the pineal gland, and its secreted molecules: serotonin, melatonin and N,N-dimethyltryptamine. We will describe historical background information and past research on the subject, as well as discuss the more recent information and how they can impact our current understanding of the pineal gland, and possibilities for further research.

The identification of the pineal gland as a distinct organ is attributed to Galen of Pergamon (130-200 B.C.). He first described the organ as being part of the brain, characterizing it as a gland and calling it konareion, or conarium in latin, because of its shape [1,2]. In antiquity the pineal gland was referred to as an enigmatic organ by Van Gehuchten, due to its role in creating a bridge between material and spiritual life [3].

The anatomical descriptions of Andreas Vesalius Bruxellensis
(1515-1564) was the basis for the conceptualization of the pineal gland as the "seat of the soul" by René Descartes (1596-1650), or as the organ of psychophysiological control [1,2].

Descartes was an avid defender of the Ancient Greek beliefs, which suggested that human passion altered the cognitive process, affectivity and is the creator of madness. This belief was maintained until the Renaissance period $[2,4]$.

As technology evolved, and microscopy appeared, the pineal gland has received its unofficial title as "The Third Eye", mostly because of its histological similarities to the lateral eyes of amniotic vertebrates $[1,2]$. Today this notion of a $3^{\text {rd }}$ eye is part of the photo-neuro-endocrine system, composed of the retina, central nervous system and the pineal gland [5].

Present both in diurnal and nocturnal vertebrates, the pineal gland is responsible for the secretion and release of melatonin, a hormone regulated by the circadian rhythm and suppressed by light stimuli [1]. The discovery of melatonin 
and serotonin in the pineal gland, as well as the quantitative variability based on day and night cycles was made possible due to fluorescence techniques $[6,7]$.

The beginning of melatonin research started in 1958 when Aaron B. Lerner (1920-2007) isolated, at Yale University, 100 micro grams of N-acetyl-5metoxytriptamine, extracted from 250.000 processed bovine pineal glands, the substance being called melatonin [8]. The discoveries derived from the research of melatonin has acknowledged most of the hypothesis postulated by Descartes [4]. Although humans are not considered photoperiodic beings, this hormone highlights seasonal traits that may lead to seasonal affective disorders, and in the short term, to „"jet-lag" disturbances from abrupt changes in time zones [9].

The pineal gland is now defined as a photo-neuroendocrine transducer that forms an integral part of the brain, it offers information on the circadian rhythm, thus further connecting the outside world with internal biochemical and physiological needs and functions of the human body [9].

With the start of the 19th century, mental illness began to be linked to organic causes [4]. Mark D. Altschule and Julian Kitay conducted 17 studies in which they administered pineal gland extract in patients diagnosed with schizophrenia; these results were promising, thus opening the door for further research, like modern neuroleptic studies that have managed to provide much more conclusive results [10].

Rick Strassman, author and psychiatry professor of the University of Medicine, New Mexico, has theorized that the pineal gland is capable of producing $\mathrm{N}, \mathrm{N}$-dimethyltryptamine, an extremely powerful hallucinogen, derived from tryptophan, especially under certain stress conditions like the moment of birth, the process of giving birth or the moments before death [2]. This molecule might be the one responsible for the near-death experiences reported by patients resuscitated after cardiac-death, later research underlying a cascade effect in which serotonin and endogenic opioids are also involved in these hallucinatory experiences [11-13].

$\mathrm{N}-\mathrm{N}$-dimethyl-tryptamine was first synthesized in 1931 by Richard Manske, and observed in plants by Oswaldo Goncalves de Luma in 1946 [2,12,14]. Rick Strassman has demonstrated the existence of $\mathrm{N}, \mathrm{N}$-dimethyl-tryptamine in the pineal gland of rodents $[2,11,13]$.

\section{Methods}

In making this narrative literature review I have used the NCBI website database PubMed "https://www. ncbi.nlm.nih.gov/PubMed/". By using the advanced search builder of the database, the search terms were chosen using MeSH terms with the main keyword "pineal gland" initially, followed by AND/OR "histology, histopathology, history, physiology, pharmacology, anatomy, clinical data, psychiatry, endocrinology, neurology, melatonin, DMT".
All fields of search were used, incorporating both older published articles, and the main focus was directed towards more recent articles, published in 2016, 2017 and 2018, by focusing the field of search to "Publication dates" and selecting the most recently published articles. The main search, using the keywords that appear in the title of the article, without including publishing date, revealed 14250 total articles; by using Pineal Gland AND Histology we have received a result of 5330 publications, of which 20 were selected by using [Publication dates] 2016 to present, and 100 more were selected out of the total 14250 based by the relevance to the subject, including additional search terms like "calcification", "morphometry", "rat", "clinical data", "psychiatry", "neurology", "endocrinology", "history", "pathology", "DMT", "melatonin", "physiology". The selection method was based on the total citing of the articles and the impact factor of the published research, preferring articles published in the Journal of Pineal Research. After removing duplicate citations, and excluding articles that had no clear methodology and content redundancies, the total number of articles included were 86 .

Other inclusion criteria were the English language, relevance to the topic, peer reviewed, recent information, wide geographical data. Articles incorporated were systematic reviews, narrative reviews, meta-analysis, experimental research, animal research, drug clinical trials, morphological, histological and imagistic studies, as well as historical reports. The main test species used in experiments included in the review were rodent or human species. Original articles were preferred over other reviews. Exclusion criteria included research aimed at non-endocrine, neurological and psychiatric oriented pathologies. Careful attention was paid to the correlation between non-scientific information on the pineal gland and evidence based scientific data found in the literature. All researched references have been properly cited using the Vancouver system.

Articles that were selected were chosen based on the reputation of the journal and author, accuracy of methods, analysis and coherence. Any inconsistencies or missing evidence led to the exclusion of the article from this review.

\section{Results}

\section{Anatomy}

The pineal gland is part of the epithalamus [15] and is in direct contact with the 2 recesses of the third ventricle, the pineal recess and the dorsal suprapineal recess that contains the choroidal plexus. The pineal gland is attached to the posterior part of the 3rd ventricle, between the posterior commissure and the dorsal habenular commissure [16].

The gland is situated on the sagittal line, it is solid, pine cone shaped, of red-grey color, approximately 5-9 $\mathrm{mm}$ in length and $1-5 \mathrm{~mm}$ in width. It weighs $100-180$ $\mathrm{mg}$. $[1,2]$. Its vascularization is assured by the posterior choroidal arteries and the internal cerebral veins [16]. 
The size of the pineal gland in mammals depends on the geographic location and climate, its size and activity being dependant on luminous stimulus $[2,17]$. The weight of the pineal gland is directly proportionate to its volume and parenchymal nuclear density [18].

There are anatomical variations in the localization of the pineal gland, there are two main types; type A sits proximally to the posterior side of the dyencephalus, while the elongated $\mathrm{ABC}$ type extends towards the cerebellum [1].

The photo-sensory information arrives at the pineal gland through a complex multi-neuronal pathway that starts from the retina [16,19-21]. The first part of this anatomic tract is between the retina and the central nervous system through the retinohypothalamic tract $[16,22]$. The second part is between the central nervous system and the lateral hypothalamus, where neural pathways cross towards the spinal cord and the superior cervical ganglions [16,23]. Noradrenergic postganglionar fibers pass through to the pineal gland via the conari nerves, passing through the cerebellous tentorium. Recent studies show that there are connections between the pineal gland, habenular nucleus and a retino-suprachiasmatic pathway [16,24].

Another morphometrical study shows that the biggest pineal gland, in volume, is that of the human age group between 30-50 years, but also with the lowest density. A link between the height and weight of the subject, and its volume, has been established, as the mean of volume is situated in individuals over $80 \mathrm{~kg}$ in weight. The most dense pineal gland belongs to individuals with a weight between 61 and $70 \mathrm{~kg}$. Also the smallest width of the pineal gland was reported in individuals under $165 \mathrm{~cm}$ height [25].

\section{Physiology}

\section{Melatonin}

The pineal gland has an endocrine role, the main hormone secreted is melatonin [16,26]. Melatonin, or $\mathrm{N}$-acetyl-5-metoxytriptamine is an indoleamine with a molecular weight of $232 \mathrm{kDa}$ [26,27]. Its synthesis is dependant on external light, light inhibits secretion, while darkness stimulates it, using the post-ganglionar betaadrenergic sympathethic fibres of the cervical sympathethic ganglia $[16,26,28]$. Studies show that in blind subjects there is an independent rhythm of melatonin secretion [16,29].

Besides the circadian rhythm of melatonin secretion, there are more secretion rhythms to take in consideration, the ultradian rhytm [16,30], the infradian rhythm and seasonal rhythm $[1,16,31]$. For individuals living at the North Pole, during the permanent darkness of winter, melatonin secretion is at its peak values [1]. These changes, especially the seasonal ones, gives birds the ability of premonition, and for other mammals it allows seasonal hibernation, thermoregulation and reproduction $[16,32]$.

The precursor of melatonin is tryptophan, which is hydroxylated withinthepinealocytesto5-hydroxytryptophan byahydroxylase. 5 -hydroxytryptophanis the decarboxylated by the aromatic-L-amino acid decarboxylase into serotonin.
Serotonin then gets transformed into melatonin due to the methyltransferase-O-hidroxi-indole enzyme (HIOMT) $[1,12,16,26,33]$. This biochemical reaction chain is what suggested the presence of N,N-dymethyl-triptamine (DMT) in pinealocytes [10].

Most studies show that peak melatonin secretion is in the dark phase of the circadian rhythm, in both sexes [16,34]. Studies also show that tryptophan levels rise in photophase and serotonin levels lower in scotophase [1,35,36]. Apart from the circadian rhythms, there is also the ultradian rhytm [30] and seasonal rhythm. Individuals that live in the north pole have peak maximal values of melatonin during the permanent darkness of winter [1,16,31].

Using radio-immuno-assay methods the median melatonin production levels are 28,8 micrograms/day according to a study done in New York by V. Lacoste, L. Wetterberg [37].

The effects of melatonin are: antigonadotrophic [16] with atrophic effects on the sexual organs, an effect that is highly dependant on the seasonal rhythm of secretion, thus having potential paradoxical effects [31]. Other effects of melatonin are: downregulation of thyroid activity [16,38,39], hypothermic [16], sleep inducing [1], hypotensive by increasing norepinefrine levels, regulating cardiac beta receptors and increasing mesenteric arterial dilation capacity, $[33,40-42]$, Iimmuno-regulatory by using the NFKB transcription factor and binding to $\mathrm{KB}$ receptors, regulating synthesis rates of glucocorticoids and melatonin[1,43,44], Antioxidant by inducing the Nrf2-ARE signaling pathway, and clearing free radicals $[42,45-48]$, oncostatic [1,43,49], thymic modulator [50] and neuroprotector $[42,48]$.

Melatonin receptors are represented by MT1, MT2 and MT3 receptors [26,48]. With senescence, the number of receptors start to decrease, and the incidence of neuropsychiatric disorders increases [48]. These receptors are also present in the cerebral cortex, the hippocampus, basal nuclei, diencephalon and mesencephalon [48]. Also MT receptors are located at retinal level, and also the vascularization of the retina, choroidal layer, sclera, cornea, crystalline and ciliary body. Melatonin has been documented to have a regenerative effect in corneal lesions and regulation of intraocular pressure [26].

A study shows exogenously administered melatonin might have a protective effect against $\mathrm{X}$ ray radiation [51].

\section{$\mathrm{N}, \mathrm{N}$-dymethyl-tryptamine}

$\mathrm{N}, \mathrm{N}$-dymethyl-tryptamine (DMT) is an endogenous hallucinogenic compound that is found within the pineal gland, alongside melatonin and serotonin. The role of DMT is not properly defined. Similar to endogenous opioids it might be partially responsible for perception, conscience, vision, imagination and dreaming. The main receptor it interacts with is 5-HT2A and sigma-1 [1,11-14,16].

The presence of DMT is found both in animal and vegetal species, for example the Amazonian plant Anadenanthera peregrina, which was used by the peruvian 
shamans for religious rituals, because of its psychoactive effects. DMT has been classified as a Schedule I drug in 1970 for external use. Endogenous secretion was found to be much lower than the doses used in psychoactive purposes, by external consumption $[2,13]$.

DMT is synthetised from tryptophan by the L-amino-acid-decarboxylase and the indoletiamine-Nmethyl-transferase (INMT). INMT has been found in peripheral tissues as well as pineal parenchyma, thus suggesting a multi-focal synthesis of DMT $[12,13]$. DMT has been identified in the pineal gland and brain of the rat, using gas chromatography and mass spectrometry studies done by Barker, Borjingin, Lomnicka, Strassman (2013), Barker (2018) and Jacob and Presti (2005) [11-13].

Latest research proposes that DMT be classified as a neurotransmitter, having the potential to synthetise, deposit and release at cerebral level. Its therapeutic value might reside in the treatment of depression, anxiety and schizoid psychosis $[12,13]$.

Nichols, in 2018, writes that the synthesis of DMT in humans has been discovered, initial studies showing that these quantities are too small for it to have hallucinogenic effects, but suggests a possible physiological variation that needs further research [2].

Fontanilla et al., in 2010, demonstrate that haloperidol administration significantly reduces the quantity of DMT present in the central nervous system [14].

\section{Histology}

The pineal gland is made up of follicules and lines of pinealocytes and glial tissue [52].

The cyto-architectural aspect is extremely variable. Some glands have a perfectly lobular aspect, separated by connective tissue, in others the connective tissue is much more abundant, and the parenchyma is arranged in a insular pattern [53]. The capsule of the gland is well defined by the pia mater. The pinealocytes form the pineal parenchyma and the astrocytes dominate the glial tissue [52].

An MRI study made in Iceland shows that the median volume of the pineal gland is $207 \mathrm{~mm} 3$ and 59\% of the glands have presented cysts and $20 \%$ have presented calcifications [54].

Pinealocytes have a poorly delimited cytoplasm as seen on Haematoxylin-Eosin, but using special stains like silver one can see numerous cytoplasmatic appendages. The nucleus contains numerous chromatin granules and a proeminent nucleolus [53]. These vesicles in the nucleus are positive to the immunohistochemical marker Synaptophisin [55].

A larger pineal parenchymal volume is directly proportional to the amount of secreted melatonin. This volume only contains pinealocytes. The more parenchyma is occupied by calcifications, gliosis and cysts, the more dysfunctional the glands secretory activities are [55].

Pinealocytes also stain immunohistochemically for NSE (Neuron specific enolase), and the main neurotransmitter is serotonin. The interstitial cells, the astrocytes and oligodendrocytes stain with GFAP (Glial fibrillary acidic protein), S-100, vimentin and antigen $\mathrm{C} 1$, its main neurotransmitter also being serotonin [16,56-58].

The calcifications found in the pineal gland are also called "corpora arenacea" or "acervuli" and are represented by calcified concretions. The acervuli can have either a globular or lamellar concentric shape [52]. Studies show that after the age of 30 , the incidence of calcifications is extremely high [53].

Anthony James Doyle and Graeme D. Anderson published CT studies in 2006 that have shown that the incidence of calcifications in the pineal gland has risen, one study presents rare calcifications in children, the youngest being 3 years old. In children under the age of 6 calcifications were present in 1\%. Between 8-14 years old the prevalence is of 39\%. There was no difference between sexes [59].

Baconnier et al. published in 2002 a study that shows that age and calcification presence are directly proportional, $97 \%$ of calcifications are found at ages of over 5. The presence of choroid plexus calcifications exists from a young age and should not be mistaken for intraparenchymatous calcifications [60].

In the pineal gland of children one can observe microcalcifications, thought to be a skeleton for the adult calcifications $[52,61,62]$.

There are two main categories of calcifications present in intraparenchymal calcifications of the pineal gland: the polycrystalline berry-shaped complexes and the smaller lamellar, well defined crystalline concretions [63].

Spectroscopy has shown that these crystals are made out of calcium, carbon and oxygen mostly, having similar features to the internal ear otoconia. Electron microscopy studies have detailed three types of crystals: cubical, cylindrical and hexagonal. 95\% of which are cylindrical [63].

Gliosis is variable, some glands contain small plaques and others contain huge plaques of glial tissue [53].

Cysts are a usual discovery in the pineal gland, being present in $25-40 \%$ of cases $[36,53,64]$. Most cysts are found in gliosis areas, and there are some that are covered by parenchymal epithelium or ependymal epithelium [53]. There have been cases of sudden death and acute hydrocephalus because of intracystic hemorrhage [56,64]. Symptomatic cysts are very rare and vary in size between $7 \mathrm{~mm}$ and $4.5 \mathrm{~cm}$ diameter $[56,65,66]$. The prevalence of asymptomatic cysts in adults, as shown by an MRI study, is around $23 \%$, and their evolution is benign [64]. In children, the presence of cysts is very low, a pediatric population study shows it to be around $3 \%$ [60]. Presently there is no protocol in place for monitoring asymptomatic cysts, both radiologically and surgically [65].

The cyst is made up of three layers, the glial layer, pineal layer and Rosenthal fiber layer [56]. They can be uniloculated or multiloculated [64]. The glial layer is positive for the immunohistochemical marker GFAP [56]. The cyst contains cerebrospinal fluid that is hypersignal on MRI, and 
requires differential diagnosis with atypical cystic formations, germinal cell tumors and pineal parenchymal tumors [65].

Cytologically the pineal gland specimens present hypercellularity distributed in fibrillar tissue fragments, pinealocytes are described as being big, rounded, epithelioid, poorly delimited cytoplasm and moderate nuclear pleomorphism cells. Less common are spindle cells. Intracytoplasmatic pigments have been described, and attributed to lipofuscin [67].

Pathology

Table I. General classification of pineal gland pathology [53].

\begin{tabular}{llllll} 
Congenital & Inflammatory & Vascular & Metabolic & Neoplastic \\
\hline Agenesia & Tuberculosis & Thrombosis & Batten disease & Primary \\
Malformations & Siphilis & & Tay Sachs disease & Secondary \\
Hypoplasia & Sarcoidosis & & &
\end{tabular}

\section{Non-tumoral pathology}

Pineal gland agenesia is exceptionally rare. There is a known link with a mutation of the PAX6 gene $[68,69]$. PAX6 is expressed in the telencephallus, diencephallus, caudal part of rhombencephallus, mielencephallus, spinal chord and pancreas [70].

Reece syndrome is a rare congenital disease, patients present multiple congenital anomalies. There have been cases with retinal dysplasia and associated pineal gland hypoplasia or agenesia [53].

Two lipidic deposit diseases have been reported. Batten disease presents abnormal lipidic deposits in the pinealocytes. In Tay-Sachs disease, sphingomyelin is deposited in the pinealocites, in both these diseases precocious puberty has been reported [53].

\section{Tumoral pathology}

Tumoral pathology of the pineal gland represents under $0.5 \%$ of all intracranial tumors. Although rare, there is a large spectrum of tumors that can develop at this location. The main symptoms of these tumors are headaches, nausea, vomiting, ataxia, loss of sight and mental state alterations [71].

Table II. Classification of pineal gland tumors [53,57,72-74].

\begin{tabular}{l|l|l|}
\hline Germ-cell tumors & Pineal parenchymal tumors & Structural tissue tumors \\
\hline Teratoma & Pineoblastoma & \\
Germinoma & Pineocytoma & \\
Endodermal-sinus & Intermediary differentiated & Gliomas \\
tumor & tumor & \\
Mixt germ cell tumor & Papillary tumor [72]
\end{tabular}

Metastasis in the pineal gland is very rare, but can be frequent due to the lack of examination of the pineal gland during autopsies. A review article by Tapp, in 1979, has found an incidence of 1/500 metastasis at pineal gland level, most cases being reported as melanomas [53].

Gliomas are exceptionally rare, but even cases of oligodendroglioma have been reported [75].

\section{Germ-cell tumors}

Germ-cell tumors emerge from faulty migration of primordial germinal cells in the central nervous system. These tumours classify as germinomas and embrionary carcinomas. Embrionary carcinomas can differentiate somatically or extra-embrionary. Extraembrionary differentiation leads to trophoblastic tumors like choriocarcinoma, and the Yolk-sack, implicitly the Yolksack tumor. Somatic tumors are classified as teratomas, both immature and mature [76].

Teratomas appear mostly in young adult males, under the age of 20. The tumor can be either of solid or cystic consistency, and histologically you can find tissues from all 3 germinal cell lines [53,77]. They represent 5 to $18 \%$ of primary brain tumors and are found mostly in men. The microscopic diagnosis is essential as embrionary tumors are radiosensitive while teratomas respond to chemotherapy and surgery [77].

Immunohistochemical stains for teratomas depend on the tissue being formed, but immature tissue is positive for alpha-feto-protein and has a high $\mathrm{Ki}-67$ proliferation index $[76,77]$.

Endodermal sinus tumors represent a selective growth of extra-embrionary mesoblastic tissue, they occur in ovaries and testicles mostly, and have a highgrade malignancy. The age incidence is between 15 and 30 years [53]. The tumor presents a variable architecture, predominantly reticular, sinusoidal and microcystic. Schiller-Duval bodies are pathognomonic. Immunohistochemical stains Glypican 3 and alpha-fetoprotein are positive for the tumoral cells [76,77].

Embrionary carcinoma is rarely pure, and often has a mixed component. It is represented by plaques of pleomorphic cells, with nucleoli, often with glandular or papillary architecture. This tumor has a high Ki-67 proliferation index, presents peritumoral necrosis and immunohistochemically it stains for cytokeratin, OCT $3 / 4$, PLAP and CD30 [76,77].

Choriocarcinoma is a trophoblastic tumor, with a predominantely cytotrophoblastic population, of round nucleolated mononucleated cells and multinucleated sincytiotrophoblastic cells with abundant eosinophilic cytoplasm. Immunohistochemically the cells stain for betaHCG, cytokeratins and HPL [76,77].

Germinomas have a maximum incidence after the 2 nd decade of life, and represent $50 \%$ of pineal germ-cell tumors. These are high growth rate tumors and highly infiltrative. They can metastasize through the cerebrospinal channel, and are often byphasic. They stain immunohistochemically to OCT 3/4, PLAP, c-Kit and SALL4 [53,76,77].

\section{Pineal parenchymal tumors}

The incidence of these tumors is under $1 \%$ of central nervous system primitive tumors $[57,72,73]$. These tumors can be well differentiated, like the pineocytoma, or poorly 
differentiated, as the pinealoblastoma. The pineocytoma has a tendency to be well differentiated, with a slow growth rate, with Homer-Wright or Flexner-Wintersteiner rosette formation, [73,74] while the pinealoblastoma is poorly delimitated and with a rapid growth pattern [53] with a marked hypercellularity of small, round cells with a poor cytoplasm and hyperchromatic and round nucleus [74]. An intermediate form tumor is also reported, with a mixed architecture, with uniform cells in an abundant stroma. No areas of necrosis or excessive mitosis is observed [74]. Pineocytoma is positive for Synaptophysin, Neurofilament, Chromogranin A immunostains. Intermediate pineal tumor is positive for Synaptophisin, Chromogranin A and Neurofilament and a Ki-67 index of 1-30\%. Pineoblastoma is positive to NSE, Synaptophysin, Chromogranin A, Neurofilament, partially to GFAP and has a very high Ki-67 index $[56,71,73,74]$.

The papillary tumor has been introduced in the World Health Organisation classification in the year 2007. This tumor presents a papillary architectural variability and cellular pleomorphism. It is an epithelioid tumor with papillary aspects and epithelial, ependymal and neuroendocrine differentiation. Immunohistochemically it is positive to Synaptophysin, Chromogranin A, EMA and has a low Ki-67 index [72].

\section{Discussion}

Melatonin seems to increase serotonin levels in the pineal gland, indicating a possible role in the treatment of affective disorders, after the serotoninergic theory of depression has already been proved at the end of the 1960s [4].

There are correlations between schizophrenia and melatonin deficiency. It is theorized that HIOMT deficit can lead to harmalin-like halucinogenic compounds being released $[78,79]$ or N,N-dimethyltriptamine (DMT) [2,80].

Other hypothesis: Melatonin stimulates the synthesis of prostaglandin E1 which is deficient in schizophrenia. Melatonin synthesis is decreased in winter when there is a statistical increase of people later diagnosed with schizophrenia. Patients with schizophrenia present a melanin deposit pattern which is correlated with melatonin deficit $[1,78,79,81]$.

An morphometric MRI study shows a low pineal gland volume in patients with depression, bipolar affective disorder and schizophrenia. In schizophrenic patients the volume is significantly lower [82].

Another morphometric study, which took into account the degree of calcification and the presence of cysts, shows the relationship between pineal volume and Alzheimer disease [83].

Pineal gland tumors have been reported to be in relation with anorexia nervosa, depression, attention deficit disorder, psychosis and chronic migraine [79,84].

Narcolepsy is correlated with a disturbance in melatonin secretion in the pineal gland [16].
Studies show that the quantity of serotonin present in the pineal gland is linked to tardive dyskinesia, facial orodyskinesia and parkinsonism, the symptoms are caused by the neuronal pathways the pineal gland is connected to [78].

There is evidence that suggests a low plasma level of melatonin to be linked to the degree of calcifications present in the pineal gland [78].

Precocious puberty and hypogonadism are associated with pineal gland tumors. The incidence is higher in boys. A study has found 21 cases of precocious puberty in 56 patients with pineal tumors $[1,53]$.

Pineal gland tumors are also associated with diabetus insipidus, anterior pituitary gland dysfunction and loss of vision and loss of color perception [53].

Bayliss CR, Bishop NL, and Fowler RC published an article in 1985, showing that increased proportion of calcified parenchyma leads to disturbances of the sense of direction [85].

A forensic study published by Kurtulus Dereli et al. in 2018, analyzed the role of the pineal gland in suicide victims. The secretory activity of melatonin was quantified and proved to be low in patients that have committed suicide. This is not enough to imply a direct and routine examination of the pineal gland during routine forensic autopsies, but it can provide a complementary argument for the neurobiological risk factors of suicide [86].

\section{Conclusion}

All the articles reviewed agree that the pineal gland is defined as a photo-neuro-endocrine organ that forms an integral part of the brain. It offers information on circadian and seasonal rhytms, thus connecting the outside world with the internal physiological and biochemical needs. Its role is embedded deep in complex neurological, endocrinological and psychiatric conditions and processes due to its complex pathways and secretory activity of serotonin, melatonin and N,N-dymethyl-triptamine. Further research into these molecules and their interaction with the state of consciousness is required in order to better understand the clinical and physiological significance they pose. Understanding of these molecules will also help in the screening of pineal parenchymal tumors in cases of atypical behavioral changes. There is need to quantify each effect melatonin has in immunity, homeostasis, antioxidation and neuroplasticity.

The possible therapeutic effects of DMT and its role in the pathogenesis of neurological and psychiatric pathology needs to be further researched as we have only just documented the presence of this molecule in mammal brains.

The role of calcifications is not yet fully established in current research and the chemical components and pathogenesis are not documented properly as yet, there is a pattern of correlation with neuro-psychiatric symptoms in patients of old age, with increased percentage of parenchyma calcified. 
The existence of pineal cysts might explain some cases documented as sudden death, as this area is often not investigated during routine forensic autopsies.

The incidence of metastasis in the pineal gland might not be properly reported due to the lack of routine examination of the pineal gland during autopsies.

Pineal gland parenchymal tumors and germ-cell tumors might create difficult clinical presentations due to endocrine dysfunction, possible manifestations being precocious puberty, psychosis, depression, bipolar disorder, dementia, which might lead to a fatal misdiagnosis; imaging examinations can easily detect pineal gland tumors if indicated correctly. Proper microscopic diagnosis requires specific immunohistochemical stains and clinical interpretation.

\section{References}

1. Macchi MM, Bruce JN. Human pineal physiology and functional significance of melatonin. Front Neuroendocrinol. 2004;25:177-195.

2. Nichols DE. N,N-dimethyltryptamine and the pineal gland: Separating fact from myth. J Psychopharmacol. 2018;32:3036.

3. Pende N. Endocrinologia, vol. 1. Buenos Aires: Salvat Editores, S.A.: 1937.

4. López-Muñoz F, Molina JD, Rubio G, Alamo C. An historical view of the pineal gland and mental disorders. J Clin Neurosci. 2011;18:1028-1037.

5. Pfeffer M, Korf HW, Wicht H. Synchronizing effects of melatonin on diurnal and circadian rhythms. Gen Comp Endocrinol. 2018;258:215-221.

6. Quay WB. Circadian rhytm in rat pineal serotonin and its modification of estrous cycle and photoperiod. Gen Comp Endocrinol. 1963;3:473-479.

7. Quay WB. Circadian and estrous rhythms in pineal melatonin and 5-hydroxy indole-3-acetic acid. Proc Soc Exp Biol Med. 1964; 115:710-713.

8. Lerner AB, Case JD, Takahashi Y, Lee TH, Mori W. Isolation of melatonin, the pineal gland factor that lightens melanocytes. J Am Chem Soc. 1958;80;2587-2587.

9. Stehle JH, Saade A, Rawashdeh O, Ackermann K, Jilg A, Sebestény T, et al. A survey of molecular details in the human pineal gland in the light of phylogeny, structure, function and chronobiological diseases. J Pineal Res. 2011;51:17-43.

10. Bigelow L. Some effects of aqueos pineal extract administration on schizophrenia symptoms. In: Altschule MD, editor. Frontiers on pineal physiology. Cambridge: Mild Press; 1975. pp 226-263.

11. Barker SA, Borjigin J, Lomnicka I, Strassman R. LC/ MS/MS analysis of the endogenous dimethyltryptamine hallucinogens, their precursors, and major metabolites in rat pineal gland microdialysate. Biomed Chromatogr. 2013;27:1690-1700.

12. Barker SA. N, N-Dimethyltryptamine (DMT), an Endogenous Hallucinogen: Past, Present, and Future Research to Determine Its Role and Function. Front
Neurosci. 2018;12:536.

13. Jacob MS, Presti DE. Endogenous psychoactive tryptamines reconsidered: an anxiolytic role for dimethyltryptamine. Med Hypotheses. 2005;64:930-937.

14. Fontanilla D, Johannessen M, Hajipour AR, Cozzi $\mathrm{NV}$, Jackson MB, Ruoho AE. The hallucinogen N,Ndimethyltryptamine (DMT) is an endogenous sigma-1 receptor regulator. Science. 2009;323:934-937.

15. Greenstein B, Greenstein A. Color Atlas of Neuroscience: Neuroanatomy and Neurophysiology. Thieme Flexibook. Stuttgart - New York; 2000.

16. Erlich SS, Apuzzo ML. The pineal gland: anatomy, physiology, and clinical significance. J Neurosurg. 1985;63:321-341.

17. Tan DX, Xu B, Zhou X, Reiter RJ. Pineal Calcification, Melatonin Production, Aging, Associated Health Consequences and Rejuvenation of the Pineal Gland. Molecules. 2018;23(2). pii: E301.

18. Hasegawa A, Mori W. Morphometry of the human pineal gland: relationship to the adrenal cortex. Acta Pathol Jpn. 1980;30:407-410.

19. Goldman BD, Darrow JM. The pineal gland and mammalian photoperiodism. Neuroendocrinology. 1983;37:386-396.

20. Güney M, Ayranci E, Kaplan S. Development and histology of the pineal gland in animals. Step by Step Experimental Pinealectomy Techniques in Animals for Researchers. 2013:33-52. Available from: https://www.scopus.com/ inward/record.uri?eid=2-s2.0-84892029501\&partnerID $=40$ \&md5=1f1127b611e6f96b16dce0d94021aa8d

21. Pevet P. Anatomy of the pineal gland of mammals, in Relkin R (ed): The Pineal Gland. New York: Elsevier; 1983, pp $1-75$.

22. Moore RY, Klein DC. Visual pathways and the central neural control of a circadian rhythm in pineal serotonin N-acetyltransferase activity. Brain Res. 1974;71:17-33.

23. Cardinali DP, Vacas MI, Gejman PV, Pisarev MA, Barontini M, Boado RJ, et al. The sympathetic superior cervical ganglia as "little neuroendocrine brains". Acta Physiol Lat Am. 1983;33:205-221.

24. Arunkumar KG, Jayanthi AA, Indira CK, Girijamony VK. Age- and Sex- Related Changes in Pineal Gland: A Morphological and Histological Study, American Journal of Internal Medicine. Special Issue:Toxicology. 2015;3:10-13.

25. Golan J, Torres K, Staśkiewicz GJ, Opielak G, Maciejewski R. Morphometric parameters of the human pineal gland in relation to age, body weight and height. Folia Morphol (Warsz). 2002;61:111-113.

26. Ostrin LA. Ocular and systemic melatonin and the influence of light exposure. Clin Exp Optom. 2019;102:99-108.

27. Lerner AB, Case JD. Pigment cell regulatory factors. J Invest Dermatol. 1959;32:211-221.

28. Lewy AJ, Wehr TA, Goodwin FK, Newsome DA, Markey SP. Light suppresses melatonin secretion in humans. Science. 1980;210:1267-1269.

29. Smith JA, O'Hara J, Schiff AA. Altered diurnal serum melatonin rhythm in blind men. Lancet. 1981;2:933. 
30. Reuss S, Vollrath L. Electrophysiological properties of rat pinealocytes: evidence for circadian and ultradian rhythms. Exp Brain Res. 1984;55:455-461.

31. Reiter RJ. The pineal and its hormones in the control of reproduction in mammals. Endocr Rev. 1980;1:109-131.

32. Ralph CL. Evolution of pineal control of endocrine function in lower vertebrates. Am Zoologist. 1983;23:597-605.

33. Kawashima K, Miwa Y, Fujimoto K, Oohata H, Nishino $\mathrm{H}$, Koike H. Antihypertensive action of melatonin in the spontaneously hypertensive rat. Clin Exp Hypertens A. 1987;9:1121-1131.

34. Adrendt J, Wetterberg L, Heyden T, Sizonenko PC, Paunier L. Radioimmunoassay of melatonin: human serum and cerebrospinal fluid. Horm Res. 1977;8:65-75.

35. Wurtman RJ, Moskowitz MA. The pineal organ (first of two parts). N Engl J Med. 1977;296:1329-1333.

36. Wurtman RJ, Moskowitz MA. The pineal organ (Second of two parts). N Engl J Med. 1977;296:1383-1386.

37. Lacoste V, Wetterberg L. Individual variations of rhythms in morning and evening types with special emphasis on seasonal differences, in: Wetterberg L (Ed.), Light and Biological Rhythms in Man, Pergamon Press, New York; 1993: pp. 287-304.

38. Vriend J, Gibbs FP. Coincidence of counter-antigonadal and counter-antithyroid action of melatonin administration via the drinking water in male golden hamsters. Life Sci. 1984;34:617-623.

39. Sinha BR, Chattopadhyay R, Dasgupta M, Chakraborty S. A comparative study indicates methimazole induced chemical hypothyroidism causes inhibition of pineal gland karyomorphology in three different species of animals. International Journal of Pure and Applied Zoology. 2014;2:84-94.

40. Holmes SW, Sugden D. Proceedings: The effect of melatonin on pinealectomy-induced hypertension in the rat. $\mathrm{Br} \mathrm{J}$ Pharmacol. 1976;56:360P-361P.

41. Chuang JI, Chen SS, Lin MT. Melatonin decreases brain serotonin release, arterial pressure and heart rate in rats. Pharmacology. 1993;47:91-97.

42. Porfirio MC, Gomes de Almeida JP, Stornelli M, Giovinazzo S, Purper-Ouakil D, Masi G. Can melatonin prevent or improve metabolic side effects during antipsychotic treatments? Neuropsychiatr Dis Treat. 2017;13:2167-2174.

43. Markus RP, Fernandes PA, Kinker GS, da Silveira CruzMachado S, Marçola M. Immune-pineal axis - acute inflammatory responses coordinate melatonin synthesis by pinealocytes and phagocytes. Br J Pharmacol. 2017 Nov 4. doi: 10.1111/bph.14083. [Epub ahead of print]

44. Caroleo MC, Frasca D, Nisticó G, Doria G. Melatonin as immunomodulatory in immunodeficient mice. Immunopharmacology. 1992;23:81-89.

45. Reiter RJ. Cytoprotective properties of melatonin: presumed association with oxidative damage and aging. Nutrition. 1998;14:691-696.

46. Reiter RJ, Pablos MI, Agapito TT, Guerrero JM. Melatonin in the context of the free radical theory of aging. Ann N Y Acad Sci. 1996;786:362-378.
47. Reiter RJ, Melchiorri D, Sewerynek E, Poeggeler B, Barlow-Walden L, Chuang J, et al. A review of the evidence supporting melatonin's role as an antioxidant. J Pineal Res. 1995;18:1-11.

48. Bahna SG, Niles LP. Epigenetic regulation of melatonin receptors in neuropsychiatric disorders. Br J Pharmacol. 2017 Oct 2. doi: 10.1111/bph.14058. [Epub ahead of print]

49. Karasek M, Pawlikowski M. Antiproliferative effects of melatonin and CGP 52608. Biol Signals Recept. 1999;8:7578 .

50. Dagnino-Subiabre A, Orellana JA, Carmona-Fontaine C, Montiel J, Díaz-Velíz G, Serón-Ferré M, et al. Chronic stress decreases the expression of sympathetic markers in the pineal gland and increases plasma melatonin concentration in rats. J Neurochem. 2006;97:1279-1287.

51. Alicelebić S, Mornjaković Z, Susko I, Cosović E, BeganovićPetrović A. The role of pineal gland and exogenous melatonin on the irradiation stress response of suprarenal gland. Bosn J Basic Med Sci. 2006;6:18-21.

52. Koshy S, Vettivel SK. Varying appearances of calcification in human pineal gland: a light microscopic study. J Anat Soc India. 2001;50:17-18. Available from: papers3://publication/ uuid/82501519-B706-493F-A8E6-5F116E93A7BB

53. Tapp E. The histology and pathology of the human pineal gland. Prog Brain Res. 1979;52:481-500.

54. Sigurdardottir LG, Markt SC, Sigurdsson S, Aspelund T, Fall $\mathrm{K}$, Schernhammer E, et al. Pineal gland volume assessed by MRI and its correlation with 6-Sulfatoxymelatonin levels among older men. J Biol Rhytms. 2016;31:461-469.

55. Nölte I, Lütkhoff AT, Stuck BA, Lemmer B, Schredl M, Findeisen $\mathrm{P}$, et al. Pineal volume and circadian melatonin profile in healthy volunteers: an interdisciplinary approach. J Magn Reson Imaging. 2009;30:499-505.

56. Taraszewska A, Matyja E, Koszewski W, Zaczyński A, Bardadin K, Czernicki Z. Asymptomatic and symptomatic glial cysts of the pineal gland. Folia Neuropathol. 2008;46:186-195.

57. Jouvet A, Saint-Pierre G, Fauchon F, Privat K, Bouffet E, Ruchoux MM, et al. Pineal parenchymal tumors: a correlation of histological features with prognosis in 66 cases. Brain Pathol. 2000;10:49-60.

58. Klein MT, Teitler M. Distribution of 5-ht(1E) receptors in the mammalian brain and cerebral vasculature: an immunohistochemical and pharmacological study. $\mathrm{Br} \mathrm{J}$ Pharmacol. 2012;166:1290-1302.

59. Doyle AJ, Anderson GD. Physiologic calcification of the pineal gland in children on computed tomography: prevalence, observer reliability and association with choroid plexus calcification. Acad Radiol. 2006;13:822-826.

60. Whitehead MT, Oh C, Raju A, Choudhri AF. Physiologic pineal region, choroid plexus, and dural calcifications in the first decade of life. AJNR Am J Neuroradiol. 2015;36:575580 .

61. Afroz H, Asm N, Ara S, Rahman M, Ha P. Microscopic study on the shape of pineal calcification of Bangladeshi cadavers, J Dhaka Med Coll. 2013;22:151-155.

62. Galliani I, Frank F, Gobbi P, Giangaspero F, Falcieri E. 
Histochemical and ultrastructural study of human pineal gland in the course of aging. J Submicrosc Cytol Pathol. 1989;21: 571-578.

63. Baconnier S, Lang SB, Polomska M, Hilczer B, Berkovic G, Meshulam G. Calcite microcrystals in the pineal gland of the human brain: first physical and chemical studies. Bioelectromagnetics. 2002;23:488-495.

64. $\mathrm{Pu}$ Y, Mahankali S, Hou J, Li J, Lancaster JL, Gao JH, et al. High prevalence of pineal cysts in healthy adults demonstrated by high-resolution, noncontrast brain MR imaging. AJNR Am J Neuroradiol. 2007;28:1706-1709.

65. Ramji S, Touska P, Rich P, MacKinnon AD. Normal neuroanatomical variants that may be misinterpreted as disease entities. Clin Radiol. 2017;72:810-825.

66. Fetell MR, Bruce JN, Burke AM, Cross DT, Torres RA, Powers JM, et al. Non-neoplastic pineal cysts. Neurology. 1991;41:1034-1040.

67. Jiménez-Heffernan JA, Bárcena C, Agra C, Asuncion A. Cytologic features of the normal pineal gland of adults. Diagn Cytopathol. 2015;43:642-645.

68. Mitchell TN, Free SL, Williamson KA, Stevens JM, Churchill AJ, Hanson IM, et al. Polymicrogyria and absence of pineal gland due to PAX6 mutation. Ann Neurol. 2003;53:658-663.

69. Al-Owain M, Al-Zahrani J, Al-Bakheet A, Abudheim N, AlYounes B, Aldhalaan H, et al. A novel syndrome of abnormal striatum and congenital cataract: evidence for linkage to chromosomes 11. Clin Genet. 2013;84:258-264.

70. Cox MA, Davis M, Voin V, Shoja M, Oskouian RJ, Loukas M, et al. Pineal Gland Agenesis: Review and Case Illustration. Cureus. 2017;9: e1314.

71. Raleigh DR, Solomon DA, Lloyd SA, Lazar A, Garcia MA, Sneed PK, et al. Histopathologic review of pineal parenchymal tumors identifies novel morphologic subtypes and prognostic factors for outcome. Neuro Oncol. 2017;19:78-88.

72. Poulgrain K, Gurgo R, Winter C, Ong B, Lau Q. Papillary tumour of the pineal region. J Clin Neurosci. 2011;18:10071017.

73. Treumann S, Buesen R, Gröters S, Eichler JO, van Ravenzwaay B. Occurrence of Pineal Gland Tumors in Combined Chronic Toxicity/Carcinogenicity Studies in Wistar Rats. Toxicol Pathol. 2015;43:838-843.

74. Yamane $\mathrm{Y}$, Mena $\mathrm{H}$, Nakazato Y. Immunohistochemical characterization of pineal parenchymal tumors using novel monoclonal antibodies to the pineal body. Neuropathology. 2002;22:66-76.

75. Naqvi S, Rupareliya C, Shams A, Hameed M, Mahuwala Z, Giyanwani PR. Pineal Gland Tumor but not Pinealoma: A Case Report. Cureus. 2017;9:e1576.

76. Vasiljevic A, Szathmari A, Champier J, Fèvre-Montange M, Jouvet A. Histopathology of pineal germ cell tumors. Neurochirurgie. 2015;61:130-137.

77. Nagasawa DT, Lagman C, Sun M, Yew A, Chung LK, Lee SJ, et al. Pineal germ cell tumors: Two cases with review of histopathologies and biomarkers. J Clin Neurosci. 2017;38:23-31.

78. Sandyk R, Kay SR. The relationship of pineal calcification and melatonin secretion to the pathophysiology of tardive dyskinesia and Tourette's syndrome. Int $\mathrm{J}$ Neurosci. 1991;58:215-247.

79. Mittal VA, Karlsgodt K, Zinberg J, Cannon TD, Bearden $\mathrm{CE}$. Identification and treatment of a pineal region tumor in an adolescent with prodromal psychotic symptoms. Am J Psychiatry. 2010;167:1033-1037.

80. Shen HW, Jiang XL, Winter JC, Yu AM. Psychedelic 5-methoxy-N,N-dimethyltryptamine: metabolism, pharmacokinetics, drug interactions, and pharmacological actions. Curr Drug Metab. 2010;11:659-666.

81. Antón-Tay F, Díaz J, Fernández-Guardiola A. On the effect of melatonin upon human brain. Its possible therapeutic implications. Life Sci I. 1971;10:841-850.

82. Findikli E, Inci MF, Gökçe M, Findikli HA, Altun H, Karaaslan MF. Pineal gland volume in schizophrenia and mood disorders. Psychiatr Danub. 2015;27:153-158.

83. Matsuoka T, Imai A, Fujimoto H, Kato Y, Shibata K, Nakamura K, et al. Reduced Pineal Volume in Alzheimer Disease: A Retrospective Cross-sectional MR Imaging Study. Radiology. 2018;286:239-248.

84. Madhusoodanan S, Ting MB, Farah T, Ugur U. Psychiatric aspects of brain tumors: A review. World J Psychiatry. 2015;5:273-285.

85. Bayliss CR, Bishop NL, Fowler RC. Pineal gland calcification and defective sense of direction. Br Med J (Clin Res Ed). 1985;291:1758-1759.

86. Kurtulus Dereli A, Demırci GN, Dodurga Y, Özbal S, Cankurt U, Boz B, et al. Evaluation of human pineal gland acetylserotonin O-methyltransferase immunoreactivity in suicide: A preliminary study. Med Sci Law. 2018;58:233-258. 